\title{
Diagnostic accuracy of the core components of a multi-parametric cardiovascular magnetic resonance imaging protocol: a CE-MARC sub-study
}

\author{
John P Greenwood ${ }^{1 *}$, David P Ripley ${ }^{1}$, Manish Motwani ${ }^{1}$, Julia Brown ${ }^{2}$, Jane Nixon ${ }^{2}$, Colin C Everett ${ }^{2}$, Neil Maredia ${ }^{1}$, \\ Petra Bijsterveld ${ }^{1}$, Sven Plein ${ }^{1}$
}

From 17th Annual SCMR Scientific Sessions

New Orleans, LA, USA. 16-19 January 2014

\section{Background}

The CE-MARC study was the largest prospective evaluation of the diagnostic accuracy of cardiovascular magnetic resonance (CMR) in coronary artery disease (CAD), demonstrating its superiority over single-photon emission computed tomography [1]. The trial adopted a multi-parametric protocol assessing ventricular function, myocardial perfusion, viability (with late gadolinium enhancement (LGE)) and coronary artery anatomy. There have been a number of previous studies analysing the diagnostic accuracy of different components of the CMR examination with contrasting results. We assessed the diagnostic accuracy of the individual components and selected combinations of the multi-parametric CMR examination from the CE-MARC study.

\section{Methods}

All patients from the CE-MARC population were studied. Visual CMR analyses were from the original, blinded read. Pre-specified sub-analysis of the four individual core components of the CMR protocol was performed in isolation, as a paired component (perfusion and LGE) and as a triplet (perfusion, LGE and ventricular function) and compared to the full multi-parametric protocol.

\section{Results}

Both CMR and X-ray angiography were available in 676 patients. The sensitivity of the combined CMR protocol

${ }^{1}$ Multidisciplinary Cardiovascular Research Centre (MCRC) \& Leeds Institute of Genetics, Health and Therapeutics, University of Leeds, Leeds, UK Full list of author information is available at the end of the article was $86.5 \%$, specificity $83.4 \%$, PPV $77.2 \%$ and NPV $90.5 \%$. The diagnostic accuracy of the individual components and paired and triplet combinations compared to the full multi-parametric protocol are presented in Table 1 and Figure 1. The maximum sensitivity for the detection of significant CAD by CMR was achieved when all four components were used. No individual component; paired perfusion with LGE; or perfusion with LGE and function significantly outperformed the multi-parametric protocol in terms of sensitivity. However in terms specificity, the individual components of perfusion, ventricular function and late gadolinium enhancement (LGE) all performed significantly better than the multi-parametric protocol ( $\mathrm{P}$ $<0.0001$ ). In addition, combining LGE with perfusion or with perfusion and ventricular function significantly improved the test specificity compared to the multi-parametric protocol $(\mathrm{P}<0.0001$ for each). In terms of PPV and NPV, the multi-parametric protocol performed significantly better than all individual components, paired or triplet combination.

\section{Conclusions}

A combined multi-parametric CMR protocol has higher sensitivity, PPV and NPV that the individual components however the specificity of the individual components of perfusion, ventricular function and late gadolinium enhancement (LGE) all performed significantly better than the multi-parametric protocol.

\section{Funding}

This study was funded by the British Heart Foundation (RG/05/004). J.P.G and S.P. received research grant 
Table 1 Diagnostic accuracy of a multi-parametric CMR exam and its core components compared to the reference test X-ray angiography.

\begin{tabular}{|c|c|c|c|c|}
\hline & Sensitivity $(95 \% \mathrm{Cl})$ & Specificity $(95 \% \mathrm{Cl})$ & $\begin{array}{c}\text { PPV } \\
(95 \% \mathrm{Cl})\end{array}$ & $\begin{array}{c}\text { NPV } \\
(95 \% \mathrm{Cl})\end{array}$ \\
\hline $\begin{array}{l}\text { Overall multi-parametric CMR study } \\
\quad \text { (all components) }(\mathrm{n}=676)\end{array}$ & $\begin{array}{c}86.5 \\
(81.8,90.1) \\
\end{array}$ & $\begin{array}{c}83.4 \\
(79.5,86.7) \\
\end{array}$ & $\begin{array}{c}77.2 \\
(72.1,81.6) \\
\end{array}$ & $\begin{array}{c}90.5 \\
(87.1,93.0) \\
\end{array}$ \\
\hline \multicolumn{5}{|c|}{ Single CMR components } \\
\hline LGE $(n=674)$ & $\begin{array}{c}40.8 \\
(35.0,46.8)\end{array}$ & $\begin{array}{c}95.8 \\
(93.4,97.4)\end{array}$ & $\begin{array}{c}86.4 \\
(79.3,91.3)\end{array}$ & $\begin{array}{c}71.4 \\
(67.5,75.0)\end{array}$ \\
\hline Perfusion $(n=661)$ & $\begin{array}{c}76.9 \\
(71.4,81.6)\end{array}$ & $\begin{array}{c}91.8 \\
(88.7,94.1)\end{array}$ & $\begin{array}{c}85.8 \\
(80.8,89.7)\end{array}$ & $\begin{array}{c}86.0 \\
(82.4,89.0)\end{array}$ \\
\hline Ventricular function ( $n=676$ ) & $\begin{array}{c}47.4 \\
(41.4,53.4)\end{array}$ & $\begin{array}{c}93.7 \\
(90.9,95.6)\end{array}$ & $\begin{array}{c}82.9 \\
(76.1,88.1)\end{array}$ & $\begin{array}{c}73.3 \\
(69.3,76.9)\end{array}$ \\
\hline MRA $(n=597)^{* *}$ & $\begin{array}{c}71.2 \\
(65.1,76.7)\end{array}$ & $\begin{array}{c}89.8 \\
(86.3,92.5)\end{array}$ & $\begin{array}{c}81.8 \\
(75.9,86.5)\end{array}$ & $\begin{array}{c}83.0 \\
(79.0,86.4)\end{array}$ \\
\hline \multicolumn{5}{|c|}{ Combinations } \\
\hline $\begin{array}{l}\text { Perfusion/LGE } \\
\quad(n=676)\end{array}$ & $\begin{array}{c}78.6 \\
(73.3,83.1)\end{array}$ & $\begin{array}{c}89.3 \\
(85.9,91.9)\end{array}$ & $\begin{array}{c}82.6 \\
(77.5,86.8)\end{array}$ & $\begin{array}{c}86.5 \\
(82.9,89.5)\end{array}$ \\
\hline $\begin{array}{l}\text { Perfusion/LGE/ventricular function } \\
\qquad(\mathrm{n}=676)\end{array}$ & $\begin{array}{c}81.6 \\
(76.5,85.8)\end{array}$ & $\begin{array}{c}85.9 \\
(82.1,88.9)\end{array}$ & $\begin{array}{c}78.9 \\
(73.7,83.3)\end{array}$ & $\begin{array}{c}87.8 \\
(84.2,90.6)\end{array}$ \\
\hline
\end{tabular}

CMR - cardiovascular magnetic resonance; LGE - late gadolinium enhancement; MRA - magnetic resonance angiography. ${ }^{*}$ Only includes excellent or adequate quality MRA

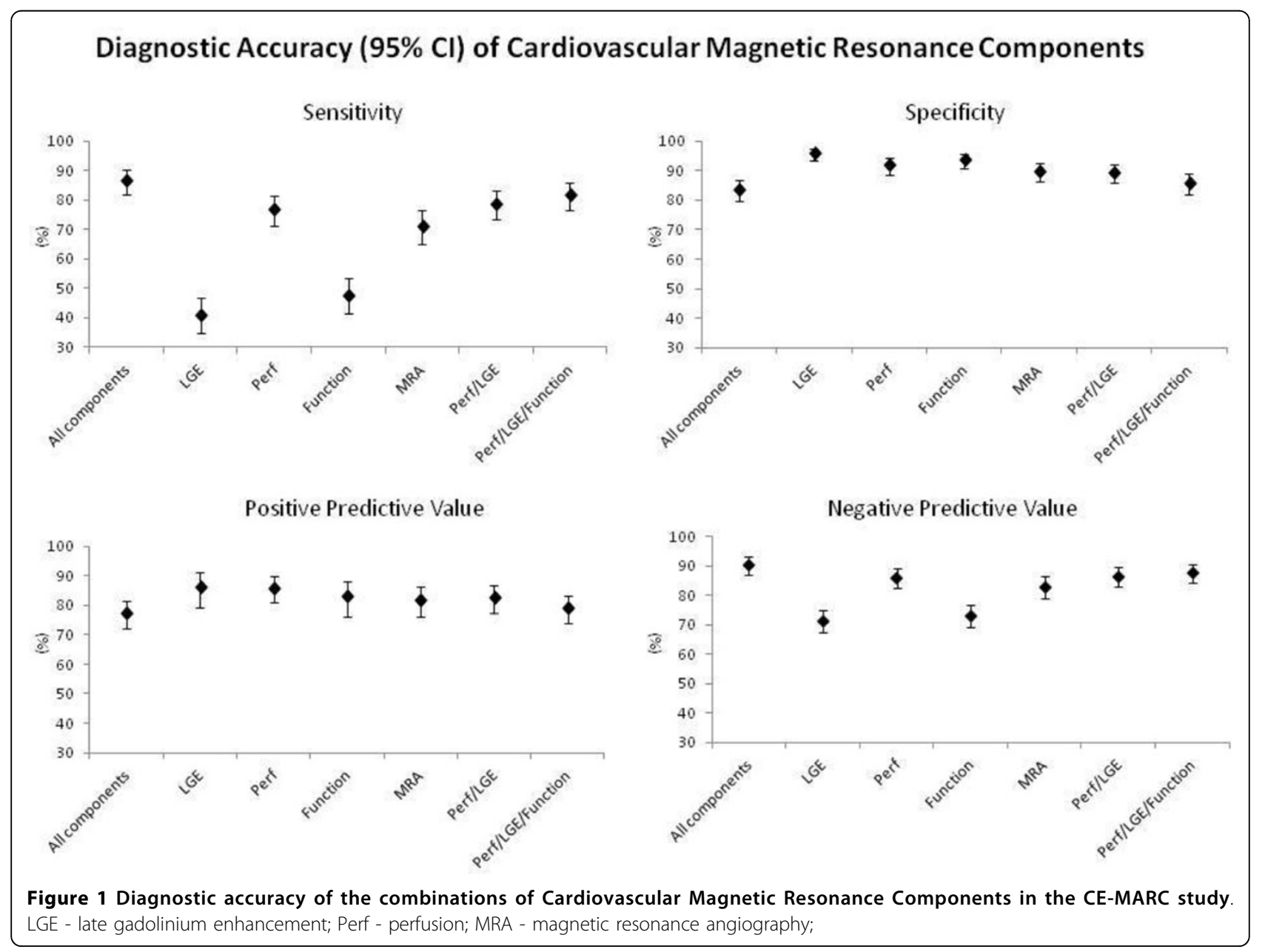


from Philips Healthcare. S.P. is funded by a British Heart Foundation fellowship (FS/10/62/28409).

\section{Authors' details}

${ }^{1}$ Multidisciplinary Cardiovascular Research Centre (MCRC) \& Leeds Institute of Genetics, Health and Therapeutics, University of Leeds, Leeds, UK. ${ }^{2}$ Clinical Trials Research Unit, University of Leeds, Leeds, UK.

Published: 16 January 2014

\section{Reference}

1. Greenwood JP, Maredia N, Younger JF, Brown JM, Nixon J, Everett CC, et al: Cardiovascular magnetic resonance and single-photon emission computed tomography for diagnosis of coronary heart disease (CEMARC): a prospective trial. Lancet 2012, 379(9814):453-60.

doi:10.1186/1532-429X-16-S1-019

Cite this article as: Greenwood et al: Diagnostic accuracy of the core components of a multi-parametric cardiovascular magnetic resonance imaging protocol: a CE-MARC sub-study. Journal of Cardiovascular Magnetic Resonance 2014 16(Suppl 1):019.

\section{Submit your next manuscript to BioMed Central} and take full advantage of:

- Convenient online submission

- Thorough peer review

- No space constraints or color figure charges

- Immediate publication on acceptance

- Inclusion in PubMed, CAS, Scopus and Google Scholar

- Research which is freely available for redistribution

Submit your manuscript at www.biomedcentral.com/submit 